\title{
PENGARUH REPUTASI, KUALITAS RELASIONAL DAN KEPERCAYAAN PASIEN TERHADAP KEPUASAN DAN LOYALITAS PASIEN Studi Kasus pada Pasien Rawat Jalan BPJS di Rumah Sakit Swasta Kota Tangerang
}

ENENG WILIANA, LENA ERDAWATI DAN YANTHI MEITRY

Fakultas Ekonomi dan Bisnis, Universitas Muhammadiyah Tangerang

Current government policy requires all hospitals to collaborate with BPJS. The phenomenon that often occurs in some hospitals, is the difference in services between BPJS and non BPJS patients. The purpose of this study was to determine and analyze the effect of reputation, relational quality and trust on BPJS patient satisfaction and loyalty in private hospitals in the city of Tangerang, both partially and simultaneously. And to find out and analyze the effect of satisfaction on BPJS patient loyalty in private hospitals in the city of Tangerang. The research method used is causal research used to prove the cause and effect relationship of several variables. Data collection techniques used were the method of observation, interviews and questionnaires relating to reputation, relational quality, trust in customer satisfaction and customer loyalty. Where the sample used was outpatients in 3 (three) Private Hospitals that have performed BPJS services with well. The analysis technique used is Path Analysis. The results of the analysis show reputation, relational quality, trust affect patient satisfaction and loyalty both partially and simultaneously. And satisfaction affects the loyalty of BPJS outpatients in three private hospitals in the city of Tangerang.

Keywords: Reputation, Relational Quality, Trust, Patient Satisfaction, Loyalty 


\section{PENDAHULUAN}

Hakikat dasar dari penyelenggaraan pelayanan kesehatan di rumah sakit adalah pemenuhan kebutuhan dan tuntutan dari para pemakai jasa pelayanan kesehatan (pasien) dimana pasien mengharapkan suatu penyelesaian dari masalah kesehatannya pada rumah sakit. Oleh karena itu pasien memandang bahwa rumah sakit harus lebih mampu dalam hal pemberian pelayanan medik dalam upaya penyembuhan dan pemulihan yang berkualitas, cepat tanggap atas keluhan serta penyediaan pelayanan kesehatan yang nyaman. $\mathrm{Ru}-$ mah Sakit sebagai tempat pelayanan kesehatan diharapkan memberikan pelayanan prima kepada pasien.(Irmawati,2014)

Kebijakan pemerintah sekarang ini mewajibkan seluruh rumah sakit untuk bekerjasama dengan BPJS Kesehatan tentu tidak lain untuk melindungi pasien miskin saat berobat ke rumah sakit. Fenomena yang sering terjadi di beberapa rumah sakit, adanya perbedaan pelayanan antarapasien BPJS dan non BPJS, namun di beberapa rumah sakit swasta di Kota Tangerang menerapkan tidak adanya perbedaan pelayanan, tidak ada pembatasan jam pelayanan untuk rawat jalan serta tidak ada sistem kuota atau pembatasan jumlah tempat tidur untuk rawat inap.

Berdasarkan data Indeks Kepuasan Masyarakat di Kota Tangerang tahun 2018, didapatkan fakta bahwa pasien biasanya mempunyai pengalaman tidak menyenangkan, bahkan menakutkan ketika datang ke Rumah Sakit, karena pelayanan yang didapatkan tidak maksimal dan cenderung merugikan pasien dan hal tersebut bisa menimbulkan ketidakpuasan. Pernyatan pasien yang terangkum, menyampaikan bahwa dokternya terkesan terburu-buru dan menakut-nakuti atas penyakit yang diderita pasien, perawat yang cuek dan kurang informatif.

Berdasarkan beberapa hal di atas, maka dilakukan tujuan penelitian ini adalah untuk mengetahui dan menganalisa pengaruh reputasi, kualitas relasional dan kepercayaan terhadap kepuasan pasien BPJS di Rumah sakit swasta di Kota Tangerang baik secara parsial maupun simultan. Serta Untuk mengetahui dan menganalisa pengaruh reputasi, kualitas relasional dan kepercayaan terhadap loy- alitas pasien BPJS di Rumah sakit swasta di Kota Tangerang baik secara parsial maupun simultan. Juga untuk mengetahui dan menganalisa pengaruh kepuasan terhadap loyalitas pasien BPJS di Rumah sakit swasta di Kota Tangerang.

\section{TINJAUAN PUSTAKA}

\section{Reputasi Perusahaan}

Dalam Maria (2014) disebutkan bahwa terdapat beberapa aspek dalam membentuk reputasi perusahaan, antara lain kemampuan finansial, mutu produk dan pelayanan, fokus pada pelanggan, keunggulan dan kepekaan sdm, reliability, inovasi, tanggung jawab lingkungan, tanggung jawab sosial, dan penegakan good corporate governance (GCG).

Reputasi korporasi setidaknya perlu diperhatikan beberapa hal sebagai berikut: (1) Eksekutif perusahaan di seluruh dunia umumnya percaya bahwa perusahaan dapat mempengaruhi reputasinya sendiri; (2) Reputasi kokoh' (strong reputation) punya tiga jenis manfaat strategis dan tujuan yang dapat disimak dan dibedakan berdasarkan hasil penelitian empiris; (3) Pada dasarnya ada enam faktor kunci yang dapat menjadi pemupuk reputasi. Faktor-faktor kunci pemupuk reputasi ini dapat tampil dengan bobot yang berbeda-beda menurut negara, jenis industri dalam suatu negara, dan teristimewa tujuan strategisnya. (4) Akhirnya, faktor utama penghambat reputasi pada dasarnya adalah perilaku perusahaan, khususnya yang berkaitan dengan 'harapanharapan masyarakat' (public expectations).

Delapan Kunci ini kemudian digunakan sebagai tolok ukur untuk menentukan 'perusahaan unggulan' (most admired companies), dan meliputi hal-hal berikut ini: (Fortune, Vol. 141, No. 4 February 2000).

a. semangat pembaharuan (innovativeness);

b. mutu manajemen (quality of management);

c. kualitas potensi karyawan (employee talent);

d. kesehatan keuangan (financial soundness);

e. kebijakan pemanfaatan aset-aset perusahaan (use of corporate assets);

f. nilai investasi jangka panjang (long-term investment values);

g. tanggung jawab sosial (social responsibility);

h. mutu produk/jasa (quality of products/services). 


\section{Kualitas Relasional}

Pemasaran relasional menurut Chen, Chiu, Chen, and Liao (2011 : 17) adalah pemasaran yang memiliki pendekatan komprehensif untuk menciptakan, mempertahankan dan meningkatkan hubungan dengan konsumen.

Makna sebagai proses dalam menarik, memelihara dan meningkatkan hubungan dengan orang-orang penting atau yang memiliki pengaruh terhadap perusahaan.

Menurut Tjiptono (2012:420), terdapat tiga faktor kunci sukses implementasi kualitas relasional, yakni:

a. Kualitas Jasa Inti;

b. Segmentasi dan Pemilihan Pasar Sasaran Secara Cermat;

c. Pemantauan Berkesinambungan Terhadap Relasi yang Dibina;

Sedangkan faktor kunci sukses relationship marketing tersebut menjadi pondasi bagi pemilihan level strategi relasi yang relevan bagi organisasi:

a. Financial Bonds,

b. Social Bonds;

c. Customization Bonds;

d. Structural Bonds;

Terdapat beberapa hal yang membedakan antara pemasaran transaksional (tradisional) dengan kualitas Relasional dapat dilihat pada tabel berikut ini (Mohaghar and Ghasemi, 2011 : 457458)

\section{Kepercayaan}

Kepercayaan meruapakan hal yang penting karena menyediakan dasar untuk kerjasama masa depan dan keyakinan salah satu pihak yang kebutuhannya akan digenapi di masa depan dengan tindakan yang dilakukan oleh pihak lain. Menurut Peelen dan Beltman (2013:11) trust atau kepercayaan adalah sebuah kemauan untuk bergantung terhadap rekan yang dapat dipercayai. Dimensi yang digunakan untuk menilai trust adalah persepsi atau kepercayaan terhadap kehandalan dan integritas dari seorang mitra.

Menurut Egan (2011:120) trust atau kepercayaan mempunyai keuntungan sebagai berikut:

a. Menghasilkan perilaku yang kooperatif antara perusahaan dengan pelanggan

b. Mengurangi potensi konflik yang berbahaya bagi hubungan perusahaan dengan pelanggan

c. Memudahkan perusahaan memberikan respon yang efektif jika terjadi krisis atau konflik dalam hubungan perusahaan dengan pelanggan

\section{Kepuasan Pasien}

Memahami kebutuhan dan keinginan pasien adalah hal penting yang mempengaruhi kepuasan pasien. Pasien yang puas merupakan aset yang sangat berharga karena apabila pasien merasa puas mereka akan terus melakukan pemakaian terhadap jasa pilihannya, tetapi jika pasien merasa tidak puas mereka akan memberitahukan dua kali lebih hebat kepada orang lain tentang pengalaman buruknya. Untuk menciptakan kepuasan pasien, rumah sakit harus menciptakan dan mengelola suatu sistem untuk memperoleh pasien yang lebih banyak dan kemampuan untuk mempertahankan pasiennya.

Kotler (2014:50) menyatakan bahwa kepuasan

Tabel 1

Perbedaan pemasaran tradisional dan kualitas Relasional

\begin{tabular}{|c|c|c|}
\hline Aspek & Pemasaran tradisional & Kualitas Kerelasian \\
\hline Fokus & Fokus pada penjualan & $\begin{array}{l}\text { Fokus pada mempertahankan } \\
\text { konsumen }\end{array}$ \\
\hline Orientasi & Orientasi pada karakteristik produk & Orientasi pada manfaat produk \\
\hline Skala waktu & Skala waktu jangka pendek & Skala waktu jangka panjang \\
\hline $\begin{array}{l}\text { Komitmen } \\
\text { kepada konsumen }\end{array}$ & Komitmen terbatas & Komitmen tinggi \\
\hline Kontak & Kontak dengan konsumen rendah & Kontak dengan konsumen tinggi \\
\hline Kualitas & $\begin{array}{l}\text { Kualitas adalah urusan } \\
\text { bagian operasional }\end{array}$ & $\begin{array}{l}\text { Kualitas adalah urusan } \\
\text { semua departemen/ orang }\end{array}$ \\
\hline
\end{tabular}

Sumber: Mohaghar and Ghasemi (2011 : 457-458) 
adalah perasaan senang atau kecewa seseorang yang berasal dari perbandingan kesannya terhadap kinerja atau hasil suatu produk dan harapanharapannya. Banyak pakar mendefinisikan mengenai kepuasan pelanggan. Tjiptono (2012:111) mendefinisikan kepuasan atau ketidakpuasan pelanggan sebagai suatu tanggapan emosional pada evaluasi terhadap pengalaman pelanggan suatu produk atau jasa.

Menurut Kotler (2014;54) ada 4 metode untuk mengukur kepuasan pelanggan, yaitu:

1. Sistem Keluhan dan Saran

Setiap perusahaan yang berpusat pada pelanggan (customer centered) perlu memberikan kesempatan bagi pelanggannya untuk menyampaikan saran, pendapat, dan keluhan mereka. Banyak restoran dan hotel yang memberikan formulir bagi tamu untuk mengetahui kesukaan dan keluhan mereka. Alur informasi ini memberikan banyak gagasan baik dan perusahaan dapat bergerak cepat untuk menyelesaikan masalah.

\section{Ghost Shopping (pembeli bayangan).}

Metoda ini dilaksanakan dengan cara mempekerjakan beberapa orang (ghost shopper) untuk berperan sebagai pelanggan atau pembeli potensial produk perusahaan pesaing untuk melaporkan titik-titik kuat maupun titik-titik lemah yang mereka alami waktu membeli produk perusahaan maupun produk pesaing. Ghost shopper juga dapat mengamati cara penanganan setiap keluhan.

3. Lost Customer Analysis (analisis pelanggan yang beralih).

Perusahaan sebaiknya menghubungi para pelanggan yang telah berhenti membeli atau yang telah berpindah pemasok agar dapat memahami mengapa hal ini terjadi dan supaya dapat mengambil kebijakasanaan perbaikan atau penyempurnaan selanjutnya.

\section{Survei Kepuasan Pelanggan}

Perusahaan tidak dapat beranggapan bahwa sistem keluhan dan saran dapat menggambarkan secara lengkap kepuasan dan kekecewaan pelanggan. Perusahaan yang responsif mengukur kepuasan pelanggan dengan mengadakan survey berkala. Mereka mengirimkan daftar pertanyaan atau menelpon suatu kelompok acak dari pembeli mereka untuk mengetahui perasaan mereka terhadap berbagai aspek kinerja perusahaan. Perusa- haan juga menanyakan pendapat pembeli mengenai kinerja perusahaan pesaing.

\section{Loyalitas Pelanggan}

Menurut Tjiptono (2012:36) bahwa loyalitas konsumen itu timbul karena kepuasaan, maka loyalitas merupakan kombinasi dari kepuasaaan konsumen, rintangan beralih, pemasok dan keluhan

Seorang pelanggan yang loyal memiliki prasangka spesifik mengenai apa yang akan dibeli dan dari siapa. Pembeliannya bukan merupakan peristiwa acak. Selain itu, loyalitas menunjukkan kondisi dari durasi waktu dan mensyaratkan bahwa tindakan yang dilakukan lebih dari dua kali. (Dharmesta, B.S. 2014)

Konsumen yang loyal sangat besar artinya bagi perusahaan. Menurut Kotler (2014 : 25) ada lima indikator konsumen yang loyal yaitu:

a. Konsumen cenderung membeli lebih banyak dan setia lebih lama.

b. Konsumen cenderung melakukan cross selling atau add-on-selling.

c. Konsumen tidak sensitive terhadap harga.

d. Konsumen akan melakukan word of mouth yang positif.

e. Menawarkan gagasan barang atau jasa kepada perusahaan.

Loyalitas dapat diartikan sebagai kesetiaan, yaitu kesetiaan seseorang terhadap suatu objek. Menurut Aaker (2009), ada lima cara untuk menciptakan dan memelihara loyalitas konsumen. Pertama adalah memperlakukan hak pelanggan, yaitu pelanggan atau konsumen mempunyai hak untuk dihormati dalam artian memperlakukan mereka sesuai dengan keinginannya dan kehendak mereka, agar tetap terpelihara loyalitasnya maka perusahaan harus memperhatikan apa saja keinginan dan harapan mereka terhadap kinerja produk perusahaan. Kedua adalah tetap dekat dengan pelanggan, dimana kedekatan tersebut merupakan modal yang berharga karena perusahaan akan tahu perubahan-perubahan dari keinginan konsumen, kedekatan ini sangat efektif untuk mengetahui harapan konsumen dengan cepat. Ketiga adalah mengukur kepuasan pelanggan, dimana hal tersebut sangat penting untuk dijadikan masukan yang berarti, dan harus dilakasanakan secara kontinu dan bertahap pada setiap dekade untuk mengeta- 
hui sikap konsumen terutama mengenai loyalitas mereka. Keempat adalah menciptakan biaya-biaya peralihan antara lain berupa pemberian harga, serta potongan yang dinegosiasi yang mana harga yang telah ditetapkan dapat berkurang dengan cara negosiasi dengan pertimbangan khusus bagi para pelanggan yang setia. Kelima adalah memberikan ekstra, yang mana bisa berupa pemberian hadiah-hadiah untuk para pelanggan sehingga mereka merasa diperhatikan dan dihargai, yang pada akhirnya dapat mengikat mereka agar tetap loyal dan setia.

\section{Hipotesa Penelitian}

1. Terdapat pengaruh reputasi, kualitas relatisional dan kepercayaan terhadap kepuasan pasien rawat jalan BPJS di Rumah sakit swasta di Kota Tangerang.

2. Terdapat pengaruh reputasi, kualitas relatisional dan kepercayaan terhadap loyalitas pasien rawat jalan BPJS di Rumah sakit swasta di Kota Tangerang.

3. Terdapat pengaruh kepuasan terhadap loyalitas pasien rawat jalan BPJS di Rumah sakit swasta di Kota Tangerang

\section{METODE PENELITIAN}

Penelitian ini menggunakan penelitian yang bersifat kausal (sebab-akibat). Desain penelitian kausal digunakan untuk membuktikan hubungan sebab dan akibat dari beberapa variabel yaitu variabel reputasi, kualitas relatisional, kepercayaan dan loyalitas pasien.

Teknik pengumpulan data yang digunakan dalam penelitian ini adalah :

1. Observasi

Obervasi ini dilakukan dengan melihat kegiatan operasional Rumah Sakit Swasta dan keberadaan pasien rawat jalan BPJS yang datang.

Tabel 2

Definisi Operasional variabel

\begin{tabular}{|c|c|c|c|}
\hline No & Nama Variabel & Definisi Operasional & Indikator \\
\hline 1 & Reputasi & $\begin{array}{l}\text { suatu nilai yang diberikan } \\
\text { kepada individu, institusi atau } \\
\text { negara. Reputasi tidak bisa } \\
\text { diperoleh dalam waktu singkat } \\
\text { karena harus dibangun } \\
\text { bertahun-tahun untuk meng- } \\
\text { hasilkan sesuatu yang bisa } \\
\text { dinilai oleh publik. }\end{array}$ & $\begin{array}{ll} & \text { Kualitas produk perusahaan itu sendiri } \\
\text { - } & \text { Keuntungan dari perusahaan } \\
\text { - } & \text { Bagaimana manejemen perusahaan } \\
\text { bagaimana tanggung jawab sosial perusahaan }\end{array}$ \\
\hline 2 & $\begin{array}{l}\text { Kualitas } \\
\text { relasional }\end{array}$ & $\begin{array}{l}\text { Keterikatan antara Laris } \\
\text { Manies Shop dengan pelang- } \\
\text { gannya }\end{array}$ & $\begin{array}{ll} & \text { Cepat tanggap } \\
- & \text { Interpersonal skill (“Nyambung”) } \\
\text { - } & \text { Kepedulian. } \\
\end{array}$ \\
\hline 3 & Kepercayaan & $\begin{array}{l}\text { pengetahuan konsumen men- } \\
\text { genai suatu objek, atributnya, } \\
\text { dan manfaatnya. }\end{array}$ & $\begin{array}{ll}- & \text { Integritas } \\
- & \text { Benevolence (kebaikan hati) } \\
- & \text { Kompetensi } \\
- & \text { Predictability } \\
\text { - } & \text { Reliabilitas } \\
- & \text { Intimacy } \\
\end{array}$ \\
\hline 4 & $\begin{array}{l}\text { Kepuasan } \\
\text { pelanggan }\end{array}$ & $\begin{array}{l}\text { tolak ukur dari sebuah keber- } \\
\text { hasilan sebuah usaha }\end{array}$ & $\begin{array}{ll}\text { - } & \text { Menjaga kualitas produk barang dan jasa } \\
\text { - } & \text { Pelayanan yang ramah } \\
\text { - } & \text { Lengarkan keluhan dan saran dari pelanggan } \\
\text { - } & \text { Berkata "tidak" jika memang tidak mampu } \\
\text { - } & \text { Bengabulkan keinginan pelanggan } \\
\end{array}$ \\
\hline 5 & $\begin{array}{l}\text { Loyalitas } \\
\text { pelanggan }\end{array}$ & $\begin{array}{l}\text { kesetiaan seseorang atas } \\
\text { suatu produk, baik barang } \\
\text { atau jasa tertentu }\end{array}$ & $\begin{array}{l}\text { - } \quad \text { Konsumen yang melakukan pembelian ulang } \\
\text { secara teratur. } \\
\text { Konsumen yang membeli produk dari lini } \\
\text { produk yang lain, misalnya di samping membeli } \\
\text { buku tulis, juga membeli es krim di tempat yang } \\
\text { sama. } \\
\text { Konsumen yang mereferensikan kepada orang } \\
\text { lain. } \\
\text { Konsumen yang tidak dapat dipengaruhi oleh } \\
\text { pesaing untuk pindah }\end{array}$ \\
\hline
\end{tabular}




\section{Kuesioner}

Teknik pengumpulan data dengan melalui beberapa pertanyaan yang diajukan atau diberikan kepada responden dalam bentuk angket. Responden akan diberikan lembaran yang berisi daftar pertanyaan yang berkaitan dengan data - data yang diperlukan dalam penelitian ini. Kuesioner akan diberikan dengan menggunakan skala continuous yaitu skala 1-10.

Populasi penelitian adalah seluruh konsumen yang telah melakukan pasien rawat jalan yang menggunakan fasilitas BPJS.

Sampel yang diambil adalah pasien yang telah melakukan pemeriksaan rawat jalan menggunakan BPJS lebih dari dua kali pada rumah sakit swasta di Kota Tangerang. Rumah sakit yang menjadi sampel adalah Rumah Sakit Annisa, Rumah Sakit Asyifa, dan Rumah Sakit Pertiwi.

Teknik analisa data yang digunakan adalah Path Analysis.

\section{HASIL DAN PEMBAHASAN}

\section{Karakterstik Responden}

Pada penelitian ini responden yang digunakan sejumlah 300 orang responden. Tabel 2 menunjukan empat karakteristik dari responden yang terdiri dari jenis kelamin, usia, pendidikan, jarak rumah dengan rumah sakit dan pekerjaan.

\section{Uji Validitas}

Uji Validitas Pada Tabel 4 disajikan hasil uji validitas instrumen penelitian. Berdasarkan Tabel 4 menunjukkan bahwa seluruh indikator pernyataan dalam variabel kualitas pelayanan, kepercayaan nasabah dan loyalitas nasabah memiliki pearson correlation yang lebih besar dari 0,5 sehingga seluruh indikator tersebut telah memenuhi syarat validitas data.

\section{Uji Reliabilitas}

Berdasarkan Tabel 5 menunjukkan bahwa ketiga instrumen penelitian yaitu variabel reputasi, kepercayaan, kepuasan dan loyalitas pasien memiliki koefisien Cronbach's Alpha lebih besar dari 0,60 sehingga pernyataan pada kuesioner tersebut reliabel.

\section{Pengujian Path Analysis}

Tabel 6 menunjukkan bahwa reputasi berpengaruh positif sebesar 0,804 terhadap kepuasan pasien, dan hubungan tersebut signifikan pada level 0,05, karena nilai t-statistik lebih besar dari 1,96 yakni sebesar 11,272. Kualitas relasional berpengaruh positif sebesar 0.714 terhadap kepuasan pasien dan hubungan tersebut signifikan pada level 0,05, karena nilai t-statistik lebih besar dari 1,96 yakni sebesar 8,442 . Kepercayaan berpengaruh positif sebesar 0.819 terhadap kepuasan pasien, dan hubungan tersebut signifikan dengan nilai t sebesar 15,234 >1,96. Reputasi berpengaruh positif sebesar 0.838 terhadap loyalitas pasien, dan hubungan tersebut signifikan dengan nilai t sebesar $11,746>1,96$. Kualitas relasional berpengaruh positif sebesar 0.751 terhadap loyalitas pasien, dan hubungan tersebut signifikan dengan nilai t sebesar 69,706 > 1,96. Demikian juga kepuasan pasien berpengaruh positif sebesar 0,834 terhadap loyalitas pasien, dan hubungan tersebut signifikan dengan nilai t hitung sebesar $7,105>1,96$.

\section{KESIMPULAN}

Berdasarkan pengujian hipotesis dan pembahasan hasil penelitian, maka dapat dikemukakan hasil penelitian sebagai berikut :

Reputasi berpengaruh positif dan signifikan terhadap kepuasan pasien rawat jalan BPJS tiga Rumah Sakit Swasta di Kota Tangerang. Hal ini berarti bahwa semakin baik reputasi rumah sakit yang dibangun oleh tiga Rumah Sakit Swasta di Kota Tangerang maka akan dapat meningkatkan kepuasan pasien, begitu juga sebaliknya.

Kualitas Relasional berpengaruh positif dan signifikan terhadap kepuasan pasien rawat jalan BPJS tiga Rumah Sakit Swasta di Kota Tangerang. Hal ini berarti bahwa semakin baik kualitas relasional rumah sakit yang dibangun oleh tiga $\mathrm{Ru}-$ mah Sakit Swasta di Kota Tangerang maka akan dapat meningkatkan kepuasan pasien, begitu juga sebaliknya.

Kepercayaan berpengaruh positif dan signifikan terhadap kepuasan pasien rawat jalan BPJS tiga Rumah Sakit Swasta di Kota Tangerang. Hal ini berarti bahwa semakin tinggi tingkat keper- 
Tabel 3

Karakteristik Responden

\begin{tabular}{|c|c|c|c|}
\hline \multirow{2}{*}{ No } & \multirow{2}{*}{ Jenis Kelamin } & \multicolumn{2}{|c|}{ Jumlah } \\
\hline & & Orang & Persentase \\
\hline 1 & Laki-laki & 178 & 59 \\
\hline \multirow[t]{2}{*}{2} & perempuan & 122 & 41 \\
\hline & Jumlah & 300 & 100 \\
\hline \multirow{2}{*}{ No } & \multirow{2}{*}{ Usia } & \multicolumn{2}{|c|}{ Jumlah } \\
\hline & & Orang & Persentase \\
\hline 1 & $\leq 20$ tahun & 19 & 6 \\
\hline 2 & $21-25$ tahun & 29 & 10 \\
\hline 3 & 26 - 30 tahun & 35 & 12 \\
\hline 4 & $31-35$ tahun & 21 & 7 \\
\hline 5 & $36-40$ tahun & 42 & 14 \\
\hline 6 & 41- 45 tahun & 49 & 16 \\
\hline 7 & $46-50$ tahun & 55 & 18 \\
\hline \multirow[t]{2}{*}{8} & $\geq 50$ tahun & 50 & 17 \\
\hline & Jumlah & 300 & 100 \\
\hline \multirow{2}{*}{ No } & \multirow{2}{*}{ Pendidikan } & \multicolumn{2}{|c|}{ Jumlah } \\
\hline & & Orang & Persentase \\
\hline 1 & SMA & 103 & 34 \\
\hline 2 & Diploma & 41 & 14 \\
\hline 3 & Sarjana & 82 & 27 \\
\hline 4 & Pasca Sarjana & 74 & 25 \\
\hline \multicolumn{2}{|r|}{ Jumlah } & 300 & 100 \\
\hline \multirow{2}{*}{ No } & \multirow{2}{*}{ Jarak ke RS } & \multicolumn{2}{|c|}{ Jumlah } \\
\hline & & Orang & Persentase \\
\hline 1 & $<1 \mathrm{~km}$ & 41 & 14 \\
\hline 2 & $1-3 \mathrm{~km}$ & 74 & 25 \\
\hline 3 & $3,1-5 \mathrm{~km}$ & 30 & 10 \\
\hline 4 & $5,1-7 \mathrm{kn}$ & 63 & 21 \\
\hline 5 & $7,1-9 \mathrm{~km}$ & 44 & 15 \\
\hline 6 & Lebih 9 km & 48 & 16 \\
\hline \multicolumn{2}{|r|}{ Jumlah } & 300 & 100 \\
\hline \multirow{2}{*}{ No } & \multirow{2}{*}{ Pekerjaan } & \multicolumn{2}{|c|}{ Jumlah } \\
\hline & & Orang & Persentase \\
\hline 1 & Pelajar/Mahasiswa & 49 & 7 \\
\hline 2 & ASN & 43 & 19 \\
\hline 3 & Pegawai Swasta & 68 & 20 \\
\hline 4 & Tenaga Medis & 29 & 8 \\
\hline 5 & Profesional & 35 & 15 \\
\hline 6 & Ibu Rumah Tangga & 33 & 17 \\
\hline \multirow[t]{2}{*}{7} & Wiraswasta & 43 & 14 \\
\hline & Jumlah & 300 & 100 \\
\hline
\end{tabular}

Sumber : Data yang diolah 2019

cayaa pasien maka akan semakin meningkat pula kepuasan pasien akan kualitas relasional tiga $\mathrm{Ru}-$ mah Sakit Swasta di Kota Tangerang.

Reputasi berpengaruh positif dan signifikan terhadap loyalitas pasien rawat jalan BPJS tiga Rumah Sakit Swasta di Kota Tangerang. Hal ini berarti bahwa semakin baik reputasi rumah sakit yang dibangun oleh tiga Rumah Sakit Swasta di Kota Tangerang maka akan dapat meningkatkan loyalitas pasien, dan tentu akan meningkatkan pula pendapatan rumah sakit yang bersangkutan

Kualitas relasional berpengaruh positif dan signifikan terhadap loyalitas pasien rawat jalan BPJS tiga Rumah Sakit Swasta di Kota Tangerang. Hal ini berarti bahwa semakin baik kualitas relasional rumah sakit yang dibangun oleh tiga Rumah Sakit Swasta di Kota Tangerang maka akan dapat meningkatkan loyalitas pasien.

Kepercayaan berpengaruh positif dan signifikan terhadap loyalitas pasien pasien rawat jalan 
Tabel 4

Hasil Uji Validitas

\begin{tabular}{|c|c|c|c|c|}
\hline Variabel & & Instrumen & Pearson Correlation & Keterangan \\
\hline \multirow{6}{*}{ Reputasi } & \multirow{6}{*}{$\mathrm{X} 1$} & X1_1 & 0,844 & Valid \\
\hline & & X1_2 & 0,795 & Valid \\
\hline & & X1_3 & 0,813 & Valid \\
\hline & & X1_4 & 0,860 & Valid \\
\hline & & X1_5 & 0,864 & Valid \\
\hline & & X1_6 & 0,967 & Valid \\
\hline \multirow{9}{*}{ Kepercayaan } & \multirow{9}{*}{$\mathrm{X} 2$} & X2_1 & 0,814 & Valid \\
\hline & & $X 2 \_2$ & 0,809 & Valid \\
\hline & & X2_3 & 0,956 & Valid \\
\hline & & $X 2 \_4$ & 0,875 & Valid \\
\hline & & X2_5 & 0,867 & Valid \\
\hline & & X2_6 & 0,940 & Valid \\
\hline & & X2_7 & 0,885 & Valid \\
\hline & & $x 2 \_8$ & 0,885 & Valid \\
\hline & & X2_9 & 0,926 & Valid \\
\hline \multirow{9}{*}{$\begin{array}{l}\text { Kualitas } \\
\text { Realsional }\end{array}$} & \multirow{9}{*}{ X3 } & X2_1 & 0,814 & Valid \\
\hline & & $X 2 \_2$ & 0,809 & Valid \\
\hline & & $x 2 \_3$ & 0,956 & Valid \\
\hline & & $X 2 \_4$ & 0,875 & Valid \\
\hline & & $\times 2-5$ & 0,867 & Valid \\
\hline & & $X 2 \_6$ & 0,940 & Valid \\
\hline & & X2_7 & 0,885 & Valid \\
\hline & & $X 2 \_8$ & 0,885 & Valid \\
\hline & & X2_9 & 0,926 & Valid \\
\hline \multirow{8}{*}{ Kepuasan } & \multirow{8}{*}{$\mathrm{Y} 1$} & Y1_1 & 0,649 & Valid \\
\hline & & Y1_2 & 0,667 & Valid \\
\hline & & Y1_3 & 0,885 & Valid \\
\hline & & Y1_4 & 0,879 & Valid \\
\hline & & Y1_5 & 0,924 & Valid \\
\hline & & Y1_6 & 0,829 & Valid \\
\hline & & Y1_7 & 0,792 & Valid \\
\hline & & Y1_8 & 0,932 & Valid \\
\hline \multirow{9}{*}{ Loyalitas } & \multirow{9}{*}{ Y2 } & Y2_1 & 0,814 & Valid \\
\hline & & Y2_2 & 0,779 & Valid \\
\hline & & Y2_3 & 0,890 & Valid \\
\hline & & Y2_4 & 0,866 & Valid \\
\hline & & Y2_5 & 0,836 & Valid \\
\hline & & Y2_6 & 0,888 & Valid \\
\hline & & Y2_7 & 0,886 & Valid \\
\hline & & Y2_8 & 0,852 & Valid \\
\hline & & Y2_9 & 0,886 & Valid \\
\hline
\end{tabular}


Tabel 5

Uji reliabilitas

\begin{tabular}{|c|c|c|}
\hline Variabel & Cronbach's Alpha & Keterangan \\
\hline $\begin{array}{l}\text { Reputasi } \\
\text { Kualitas Relasional }\end{array}$ & $\begin{array}{l}0,911 \\
0,940\end{array}$ & $\begin{array}{l}\text { reliabel } \\
\text { reliabel }\end{array}$ \\
\hline Kepercayaan & 0,937 & reliabel \\
\hline Kepuasan pasien & 0,961 & reliabel \\
\hline Loyalitas pasien & 0,972 & reliabel \\
\hline \multicolumn{3}{|c|}{$\begin{array}{c}\text { Tabel } 6 \\
\text { Pengujian Statistik dan Path Analysis }\end{array}$} \\
\hline Kontruks & Original sampel & t statistik \\
\hline $\begin{array}{l}\text { Reputasi } \rightarrow \text { Kepuasan Pasien } \\
\text { Kualitas Relasional } \rightarrow \text { Kepuasan pasien }\end{array}$ & $\begin{array}{l}0,804 \\
0,714\end{array}$ & $\begin{array}{c}11,272 \\
8,442\end{array}$ \\
\hline Kepercayaan $\rightarrow$ Kepuasan pasien & 0,819 & 15,234 \\
\hline $\begin{array}{l}\text { Reputasi } \rightarrow \text { Loyalitas Pasien } \\
\text { Kualitas Relasional } \rightarrow \text { Loyalitas pasien }\end{array}$ & $\begin{array}{l}0,838 \\
0,751\end{array}$ & $\begin{array}{l}11,746 \\
9,706\end{array}$ \\
\hline Kepercayaan $\rightarrow$ Loyalitas pasien & 0,845 & 7,450 \\
\hline Kepuasan $\rightarrow$ Loyalitas Pasien & 0,834 & 7,105 \\
\hline
\end{tabular}

Sumber : Data yang diolah 2019

BPJS tiga Rumah Sakit Swasta di Kota Tangerang. Hal ini berarti bahwa semakin tinggi tingkat kepercayaan pasien maka akan semakin meningkat pula loyalitas pasien akan kualitas pelayanan tiga Rumah Sakit Swasta di Kota Tangerang, sehingga pasien akan merekomendasikan pada orang lain untuk menggunakan jasa rumah sakit yang bersangkutan.

Kepuasan pasien berpengaruh positif dan signifikan terhadap loyalitas pasien rawat jalan BPJS tiga Rumah Sakit di Kota Tangerang. Hal ini berarti bahwa semakin tinggi tingkat kepuasan pasien maka akan semakin meningkat pula loyalitas pasien akan kualitas pelayanan tiga Rumah Sakit Swasta di Kota Tangerang, sehingga pasien akan merekomendasikan pada orang lain dan setia untuk menggunakan jasa Rumah Sakit Annisa, Rumah Sakit assyifa dan Rumah Sakit Pertiwi di Kota Tangerang.

\section{SARAN}

Berdasarkan hasil penelitian dan pembahasan, maka dapat disarankan kepada pihak manajemen tiga Rumah Sakit Swasta di Kota Tangerang, sebagai berikut:

Reputasi pada tiga Rumah Sakit Swasta di Kota Tangerang sudah baik namun perlu ditingkatkan dalam hal membuat pasien untuk lebih tertarik, lebih menyukai dan mempunyai hubungan baik pada Rumah Sakit Annisa, RS Asyifa dan RS Pertiwi.

Kualitas relasional belum maksimal dijalan di Rumah sakit tersebut sehingga perlu ditingkatkan dengan cara untuk mempertahankan pelanggan dalam jangka panjang didasarkan pada pengamatan ketatnya situasi kompetisi dan kemungkinan adanya perbedaan tingkat layanan antar Rumah Sakit swasta.

Kepercayaan pasien terhadap Rumah Sakit Annisa, RS Asyifa dan RS Pertiwi di Kota Tangerang sudah sangat tinggi hendaknya selalu ditingkatkan agar pasien tetap percaya kepada $\mathrm{Ru}-$ mah Sakit tersebut dengan cara memberikan jaminan kepuasan dan keamanan pada pasien.

Kepuasan pasien terhadap Rumah Sakit Annisa, RS Asyifa dan RS Pertiwidi Kota Tangerang sudah sangat tinggi hendaknya selalu ditingkatkan agar pasien tetap puas kepada Rumah Sakit tersebut, selalu merekomendasikan Rumah Sakit kepada orang lain, sehingga loyalitas pasien akan meningkat. 


\section{REFERENSI}

Aaker, D.A. 2009. Managing Brand Equity. New York: Simon and Schuster

Andreas Chandra dan Prof. Dr. Hatane Semuel., M.S., Ritzky Karina M. R. Brahmana, S.E., M.A. Pengaruh Aktivitas Customer Relationship Marketing Terhadap Kepuasan Pelanggan Melalui Manfaat Penerapan Relationship Marketing Di Excelso Galaxy Mall Surabaya. Jurnal Manajemen Pemasaran Vol. 1, No. 1, (2013) 1-8 Universitas Kristen Petra

Aris Siregar, 2017, Pengaruh Pemasaran Relasional Dan Kualitas Pelayananterhadap Loyalitas Pelanggan Hotel Safari Labuhanbatu Utara. Jurnal Pionir LPPM Universitas Asahan Vol 2 N0.3 JuliDesember 2017.

Bowo, N.H., 2011, Analisis Pengaruh Kepercayaan Untuk Mencapai Hubungan Jangka Panjang. Jurnal Sains Pemasaran Indonesia. vol.2. no. 1. Retrived May, 2011, pp. 85-92

Basu Swastha Dharmmesta, 2014, Manajemen Pemasaran. BPFE: Yogyakarta

Pramana, i G. Y., \& Rastini, N. M., 2016, Pengaruh Kualitas Pelayanan Terhadap Kepercayaan Nasabah dan Loyalitas Nasabah Bank Mandiri Cabang Veteran Denpasar Bali. E-Jurnal Manajemen UNUD, 5(1), 706-733.

Gitosudarmo,Indriyo, 2014, Manajemen Pemasaran Cetakan Ketiga.Edisi Kedua . BPFE. Yogyakarta.

Irmawati, 2014, Manajemen Pemasaran Rumah Sakit.Buku Ajar dan Pedoman Praktis

Joel R Evans, 2013, Retail Management: a strategic approach. Pearson Higher Ed. Hofstra University.

Kotler, P. Amstrong, 2014, Manajemen Pemasaran I: Analisis, Perencanaan, Implementasi, dan Pengendalian. Jakarta: PT. Prenhalindo Indonesia.

Kotler P, Kevin Lane Keller, 2013, Manajemen Pemasaran Edisi Kedua Belas Jilid 1. Penerbit: PT. Indeks. Jakarta

Maria R. Nindita Radyati, 2014, "Sustainable Business \& Corporate Social Responsibility (CSR)". Center of Entreprenuership, Change and Third Sector) Trisakti University.

Nugroho J. Setiadi, S.E., M.M., 2015, Perilaku Konsumen. Perspektif Kontemporer pada Motif,Tujuan, dan Keinginan Konsumen. Penerbit Kencana Prenada Media Group.

Parasuraman, A., and, Dhruv Grewal, 2000, “ The impact of technology on the quality value loyalty chain: a research agenda "Journal of The Academy of Marketing Science, Vol. 28 No. 1 p. 168-174

Paul Peter, Jerry C. Olson, 2013, Perilaku Konsumen \& Strategi Pemasaran. Salemba Empat.

Pramana, i G. Y., \& Rastini, N. M., 2016. Pengaruh Kualitas Pelayanan Terhadap Kepercayaan Nasabah dan Loyalitas Nasabah Bank Mandiri Cabang Veteran Denpasar Bali. E-Jurnal Manajemen UNUD, 5(1), 706-733. 
Rangkuti, F., 2015, Riset Pemasaran. Jakarta: PT. Gramedia Pustaka Utama.

Supranto, Nandan Limakrisna, 2011, Perilaku Konsumen dan Strategi Pemasaran. Jakarta: Mitra Wacana $\mathrm{Me}$

Ulinuha, F. E., \& Abstract, 2014, Kepuasan Pasien BPJS (Badan Penyelenggara Jaminan Sosial) Terhadap Pelayanan Di Unit Rawat Jalan (URJ) Rumah Sakit Permata Medika Semarang 
